\title{
Литература
}

1. Флорида Р. Креативный класс: люди, которые меняют будущее. - М.: Издательский Дом «Классика XXI», 2007. $421 \mathrm{c}$.

2. Пономарева А.М., Игнатова Т.В. Разработка матрицы инновационно-креативного развития города на основе индексного метода // Journal of economic regulation (Вопросы регулирования экономики). 2018. T. 9. № 3. С. 37 - 47.

3. Landry Ch., Hyams J. The Creative City Index: Measuring the Pulse of the City. London: Comedy, 2012.

4. Landry Ch. Helsinki Creative City Index. Harnessing the Collective Imagination. Study Reports. - Helsinki: City of Helsinki Urban Facts. Juvenes print, 2014. 84 p. [Электронный ресурс]. https://www.hel.fi/hel2/Tietokeskus/julkaisut/pdf/14_11_24_Tutkimuskatsauksia_3_Landry.pdf

Ponomareva Alexandra Michailovna, Doctor of Economic Science, professor, Rostov state economic university (RINH) (69, B. Sadovaya str., Rostov-on-Don, 344002, Russian Federation); Southern Federal University (105/42, B. Sadovaya str., Rostov-on-Don, 344006, Russian Federation). E-mail: alexandra22003@rambler.ru

Ponomarev Maxim Alexandrovich, Candidate of Economic Science, Docent, South-Russia Institute of Management - branch of Russian Presidential Academy of National Economy and Public Administration (70/54, Pushkinskaya St., Rostov-on-Don, 344002, Russian Federation). E-mail: maxuu@gmail.com

\section{TERRITORY BRAND RANKINGS AS A BRAND MANAGEMENT TOOLS}

\section{Abstract}

The article describes the existing ratings / indices of territories, assesses the possibility of their use in studies of territorial brands. Based on the analysis of the content and metrics of territorial ratings / indices, their classification has been developed, a rating / index system for marketing assessment of a territorial brand has been systematized, and the possibilities of existing territorial indices / ratings usage in the field of territorial brand management have been outlined.

Keywords: territory rating, country rating, city rating, territory index, country index, city index, city marketing, territory marketing, city branding, brand management.

\section{References}

1. Florida R. Kreativnyj klass: lyudi, kotorye menyayut budushchee. - M.: Izdatel'skij Dom «Klassika XXI», 2007. 421 s.

2. Ponomareva A.M., Ignatova T.V. Razrabotka matricy innovacionno-kreativnogo razvitiya goroda na osnove indeksnogo metoda // Journal of economic regulation (Voprosy regulirovaniya ekonomiki). 2018. T. 9. № 3. P. $37-47$.

3. Landry Ch., Hyams J. The Creative City Index: Measuring the Pulse of the City. London: Comedy, 2012.

4. Landry Ch. Helsinki Creative City Index. Harnessing the Collective Imagination. Study Reports. - Helsinki: City of Helsinki Urban Facts. Juvenes print, 2014. 84 p. [Elektronnyj resurs].

https://www.hel.fi/hel2/Tietokeskus/julkaisut/pdf/14_11_24_Tutkimuskatsauksia_3_Landry.pdf

УДК 656:339.3715:004.7

DOI: $10.22394 / 2079-1690-2019-1-3-78-84$

\section{ОРГАНИЗАЦИЯ ДОСТАВКИ ГРУЗОВ ДЛЯ ИНТЕРНЕТ-ТОРГОВЛИ С УЧЕТОМ ВОЗВРАТОВ}

\author{
Самусев \\ Николай \\ Семенович \\ аспирант, Российский университет транспорта (МИИТ) \\ Семенович \\ (127994, Россия, г. Москва, ул. Образцова, 9). \\ Павлова \\ E-mail: nssdimon@yandex.ru \\ Елена \\ кандидат экономических наук, профессор, Российский университет \\ Ивановна \\ транспорта (МИИТ) (127994, Россия, г. Москва, ул. Образцова, 9). \\ E-mail:elenaivanovna@bk.ru
}

\section{Аннотация}

Развитие интернет-торговли в России обусловило необходимость совершенствования организации доставки товаров. В статье рассмотрены актуальные тренды в организации перевозок грузов для интернет-торговли. На примере операторов DPD, IML, СДЕК, Вохbеrry проанализированы сервисы по доставке товаров. Применение метода рейтинговых оценок при выборе транспортных компаний является не полностью эффективным, т. к. не учитывает в полной мере особенности интернет-торговли. Применение методов категорий предпочтений и рейтинговых оценок в совокупности способствует оптимизации доставки товаров с учетом возвратов. Предложены основные критерии выбора транспортных компаний при возврате товаров.

Ключевые слова: интернет-торговля, транспортные компании, метод доминирующих характеристик, возврат товаров, качество товаров, логистические цепи, фулфилмент-операторы, логистические системы, курьерская служба.

Глобализация мировой экономики приводит к быстрым темпам развития интернет-торговли. Для России интернет-торговля - относительно новая отрасль, однако уже сейчас наша страна входит в топ-10 мировых рынков интернет-торговли, имея годовой оборот около 1 трлн руб. в год. 
К 2023 году отечественный рынок интернет-торговли вырастет более чем в 2 раза и достигнет 2,4 трлн руб. (рис. 1).

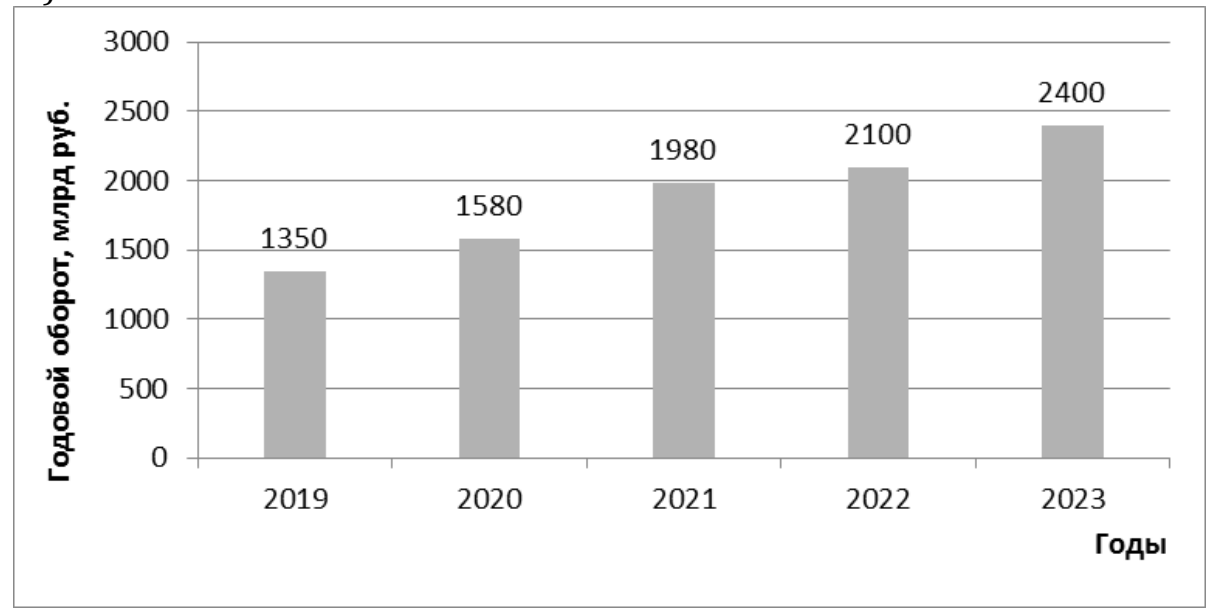

Рис. 1. Прогноз рынка интернет-торговли в России ${ }^{1}$

Количество покупателей, заказывающих товары в онлайн-магазинах, растет. В России существует 50 маркетплейсов различного профиля - Яндекс. Маркет, GoogleMerchant, Price.ru, Товары@mail.ru и др. (рис. 2).

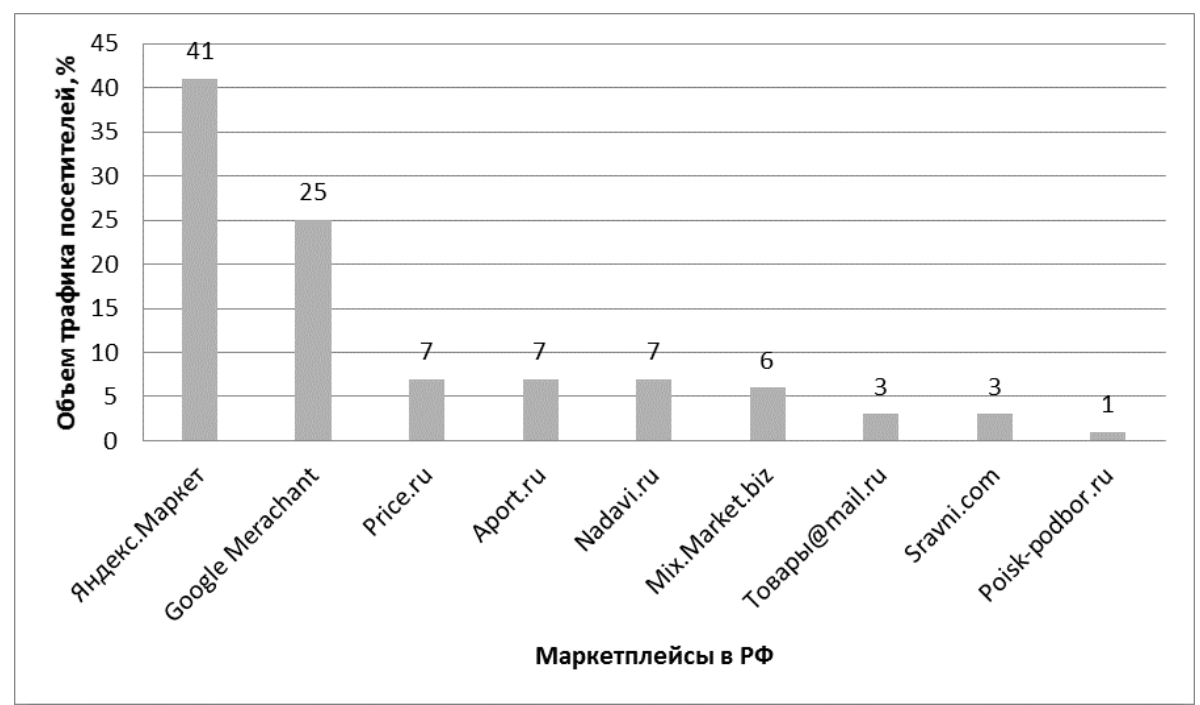

Рис. 2. Продажи в интернет-торговле на маркетплейсах в РФ (по материалам [1])

Крупнейшие российские интернет-магазины Юлмарт, Ozon, Ситилинк, ритейлер электроники и бытовой техники М-Видео развивают собственные маркетплейсы. У Почты России создан собственный проект - почта Маркет. Преимущества этого проекта - широкая сеть отделений для выдачи интернет-заказов и развитый логистический канал. Такие проекты позволяют расширить бизнес и получить дополнительную прибыль. Используя материалы Аналитического агентства Data Insight 2, целесообразно выделить основные тренды в цепях поставок онлайн торговли:

1.Спонтанные онлайн-покупки. Совершая быструю покупку через интернет, покупатель хочет получить товар в течение нескольких часов. Перед логистическими компаниями ставится задача срочной доставки товара клиенту. Главный акцент делается на время доставки.

2. Рост покупок продуктовых товаров через интернет. Это быстро растущий рынок интернетторговли. Предъявляются высокие требования к качеству доставки продуктов, температурным и влажностным режимам. Цепи поставок должны разрабатываться особенно четко, оптимизируя маршрут доставки, выбор перевозчика, подвижной состав и перевалочные пункты.

3. Развитие онлайн-магазинов электронной торговли (маркетплейсов). Сбербанк и Яндекс инвестируют 60 млрд руб. в развитие интернет-торговли в России. Поставки товаров клиентам происходят малыми партиями при большом количестве покупателей, что усложняет логистические цепи.

\footnotetext{
1 [Электронный ресурс] URL:http://datainsight.ru/sites/default/files/DI_Ecommerce\%202018.pdf

2 [Электронный ресурс] URL: https://yandex.ru/company/researches/2017/market_gfk
} 
4. Применение цифровых технологий в логистических системах, включая ИТ-технологии. Цифровизация логистических систем позволяет стандартизировать учет, обеспечивать обмен данными в кратчайшие сроки и доставлять товар покупателю за минимальную стоимость. Это способствует оптимизации цепей поставок, снижению издержек, но требует вложений в разработку и внедрение технологий.

5. Расширение сети пунктов выдачи заказов (ПВЗ) и постаматов. Покупатели заинтересованы в экономии на доставке товара за счет самовывоза. По данным Яндекс Маркет и компании GFKRUS, больше всего покупок в российских интернет-магазинах совершается самовывозом. За 2017 год 50 \% заказов покупатели забрали из ПВЗ, постаматов и магазинов. Потребители экономят на доставке. В том же году курьерской службой по доставке воспользовалось 30 \% клиентов 1 . Такая тенденция также влияет на построение схем доставки: создаются укрупненные партии поставок для ПВЗ.

6. Развитие рынка фулфилмент-операторов. Расширяют набор услуг фулфилмет-операторы TMall, Яндекс.Маркет, Goods и др.

7. Растет спрос в интернет-торговле на приобретение крупногабаритных товаров - мебели, сантехники, DIY (сделай это сам). В соответствии с этим видоизменяются требования к подвижному составу (большей грузоподъемности), используемому при доставке конечному покупателю.

8. Рост предложений от фулфилмент-операторов по работе с возвратом. Цепь поставок в этом случае трансформируется, и в ней появляется посредник, обеспечивающий возврат товаров и тары. Получает развитие реверсивная логистика.

При онлайн-покупке за рубежом 80 \% товаров были доставлены ФГУП «Почта России». К услугам курьерской доставки обратилось только 12 \% покупателей. ФГУП «Почта России» остается основной службой по доставке товаров из-за рубежа. Исторически сложилось, что в регионах эта компания имеет больше всего отделений по выдаче заказов.

На рынке транспортных услуг определяющими являются показатели: география охвата территории, стоимость и сроки доставки, качество сервиса. Задача компаний не только привлечь клиента, но и сделать его постоянным и лояльным покупателем, оптимизируя затраты и улучшая сервис. Экономически эффективным для интернет-магазинов является пользование услугами фулфилмент-операторов. Фулфилмент-операторы предоставляют комплекс услуг по приемке, хранению, обработке, упаковке и доставке товаров покупателю [2]. Используя системный подход, необходимо проанализировать условия предоставления услуг фулфилмент-операторами, для чего провести сравнительную оценку по следующим параметрам:

1) сроки поставок товаров покупателю;

2) стоимость доставки и вес товара;

3) количество ПВЗ;

4) интервалы доставки товаров.

Средние значения сроков доставки товаров курьерскими компаниями DPD, CДЕК, Boxberry, IML представлены на рис. 3.

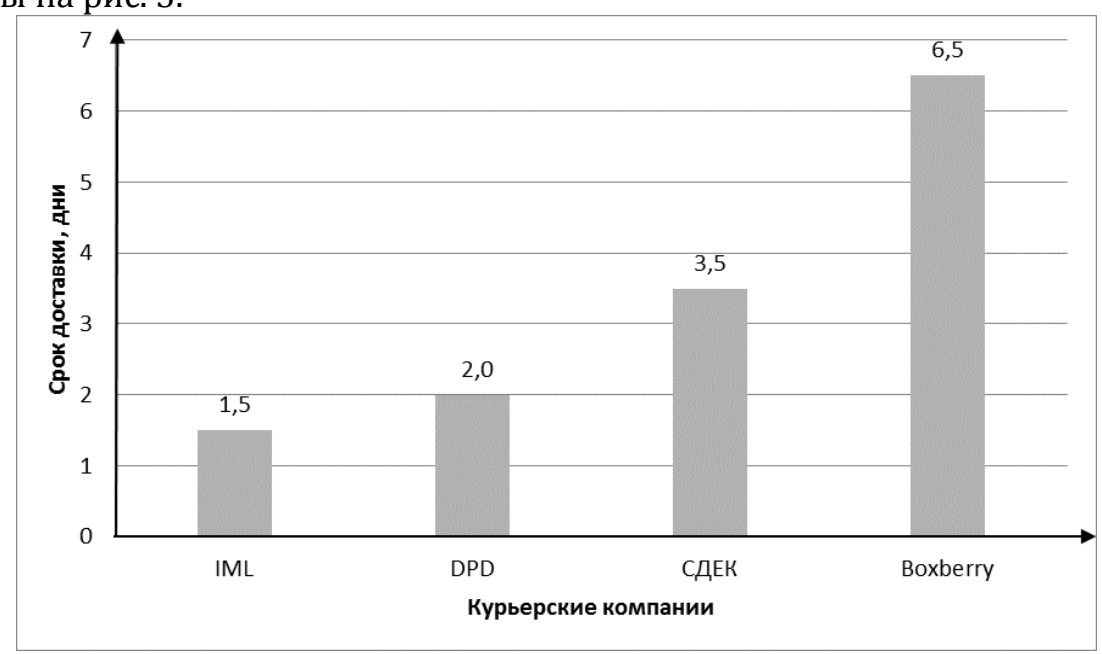

Рис. 3. Сроки поставок товаров покупателю

\footnotetext{
1 Логистические услуги для интернет-магазинов: основной доклад 2017. [Электронный pecypc] URL: http://www.engy.ru/files/data-insight---ecommerce-logistics---2017.pdf.

2 [Электронный ресурc] URL: https://www.cs-cart.ru/blog/reyting-sluzhb-dostavki-dlya-internet-magazinov/
} 
Лучшие сроки доставки товаров по России до ПВ3 предлагают компании IML и DPD, наибольшие сроки - у компании Boxberry. Логистическая составляющая в значительной степени влияет на конкурентоспособность компании, так как сроки доставки товаров в логистической цепи являются одним из основных критериев при выборе покупателем интернет-магазина.

В процессе конкурентного анализа транспортных компаний важно сравнить цены на доставку товара с учетом его веса. Цена доставки курьером у компаний СДЕК, DPD и IML составляет 250 руб., у Boxberry - 230 руб. При практически равных тарифах максимальный вес доставляемых товаров у компаний разный. Логистический сервис позволяет за 250 руб. клиенту компании DPD получить товары весом до 250 кг, клиенту компании СДЕК -до 100 кг. В то же время компания Boxberry за 230 руб. доставляет товар, ограничивая вес всего до 15 кг (рис. 4).

Для DPD и СДЕК затраты на погрузку, транспортировку товаров с большим весом существенны, но для привлечения дополнительных клиентов и увеличения грузооборота компании идут на предоставление таких услуг. Для минимизации издержек, связанных с доставкой больших грузов, DPD и СДЕК ведут работу по оптимизации цепей поставок при сохранении конкурентоспособных цен.

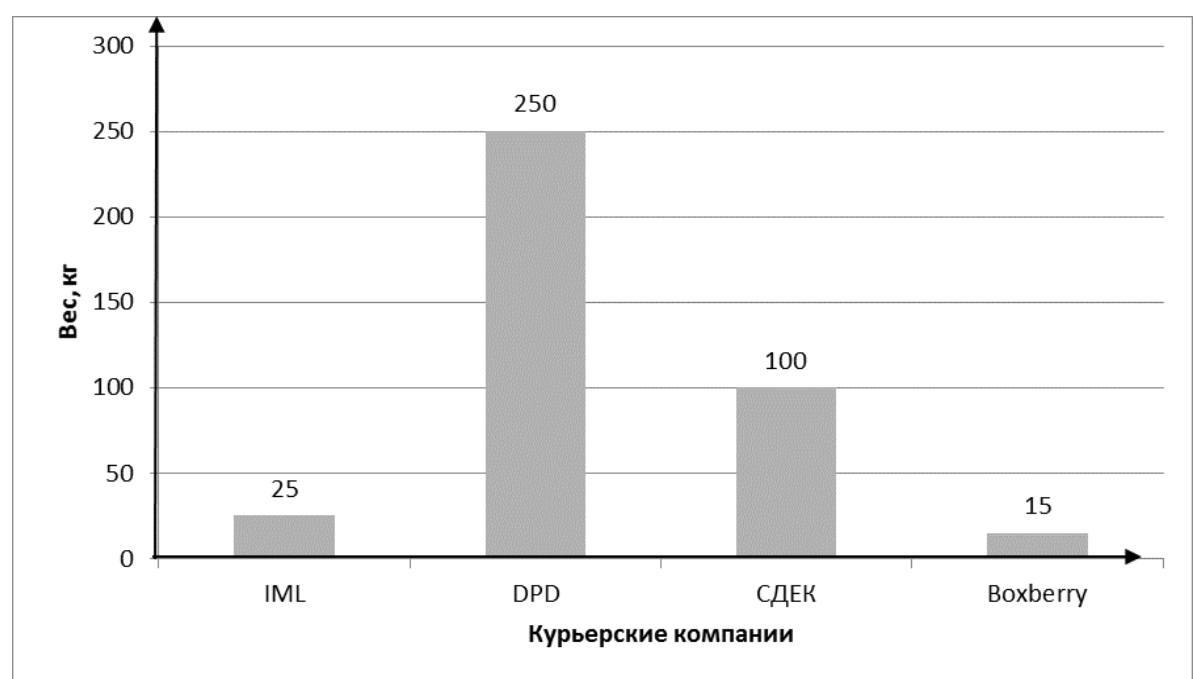

Рис. 4. Распределение транспортных компаний по весу доставляемого товара ${ }^{1}$

В процессе оптимизации цепей поставок важную роль играет «последняя миля», в связи с чем компании, бизнес которых связан с интернет-торговлей, стремятся расширять сеть пунктов выдачи заказов. Стратегической задачей логистики является выбор регионов и городов для организации ПВЗ, а также мест их расположения, удобных для клиентов. Системный подход к оптимизации цепей поставок включает анализ количественных показателей ПВЗ. Лидером в этой категории является компания DPD: у нее 2000 пунктов в 500 городах России и СНГ, наименьшее количество пунктов у IML - 500 по России (рис. 5). Большое количество ПВЗ позволяет охватить дополнительные территории и соответственно большее количество покупателей. Клиент при заказе всегда учитывает удобное место при получении товара. ПВЗ у компании DPD расположены не только в крупных городах, таких как Москва, Санкт-Петербург, Краснодар, Ростов-на-Дону и др., но и в небольших Псков, Сургут, Нефтекамск и др. География доставки товаров в интернет-торговле является немаловажным аспектом при проведении конкурентного анализа.

Компания DPD осуществляет доставку как по России, так и в страны CHГ и Европы; компания СДЕК доставляет товары по России, СНГ, Германии и Таиланду; курьерские компании Boxberry и IML -по РФ.

Еще один шаг в оптимизации путей поставок - доставка товара клиенту к определенному времени суток. Компании берут на себя обязательства выдерживать достаточно короткий временной интервал поставки, который выбирает клиент при формировании заказа. Этот сервис пока не работает в российских регионах, и получателям приходится дожидаться курьера в течение всего дня. В Москве и Санкт-Петербурге компании DPD, СДЕК, Boxberry, IML установили временные интервалы доставки в пределах 2-3 часов (табл. 1).

\footnotetext{
1 [Электронный ресурс] URL: https://www.cs-cart.ru/blog/reyting-sluzhb-dostavki-dlya-internet-magazinov/
} 


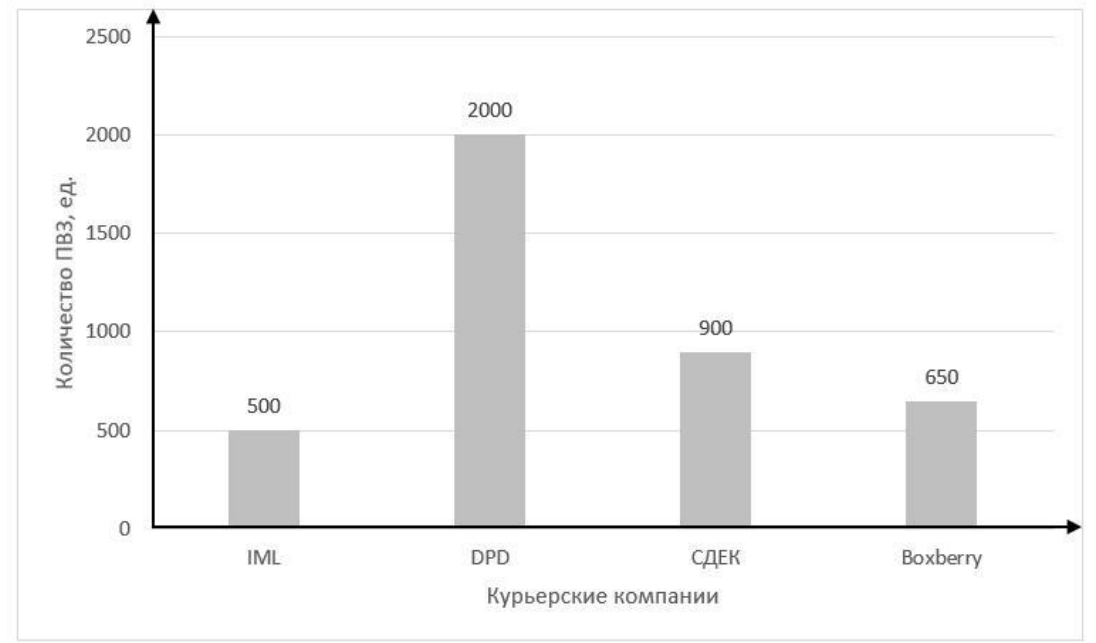

Рис. 5. Количество ПВЗ у транспортных компаний ${ }^{1}$

Временные интервалы доставки (по материалам²)

\begin{tabular}{|c|c|c|l|}
\hline Компания & Москва & Санкт-Петербург & Другие города РФ \\
\hline DPD & 2 часа & 2 часа & в течение дня \\
\hline CДЕК & 3 часа & 3 часа & в течение дня \\
\hline IML & 3 часа & 3 часа & в течение дня \\
\hline Boxberry & 4 часа & 4 часа & в течение дня \\
\hline
\end{tabular}

Сокращение временного интервала до 2 часов у компании DPD стало возможным благодаря применению цифровых технологий в цепи поставок. Были внедрены новые сервисы:

- обработка адресов доставки товаров и определение их геокоординат;

- разработка оптимального маршрута на основе результатов геокодирования 3 .

На основе системного анализ выделены два лидера среди рассматриваемых компаний - DPD и СДЕК. Компания СДЕК больше делает акцент на курьерской доставке «последняя миля», не увеличивая сеть ПВЗ, в то время, как DPD активно открывает свои ПВЗ и строит небольшие склады в регионах России. Для покупателей в регионах актуальны условия оплаты в рассрочку и кредит. Это необходимо учитывать курьерским компаниям и предусмотреть возможность более длительного хранения заказанных товаров на региональных складах.

Для покупателей в интернете важной является информация о процедуре возврата товара, причем фулфилмент-операторы и логистические провайдеры должны оптимизировать возвратные потоки. Оптимальный выбор фулфилмент-операторов должен производиться с применением методов решения многокритериальных задач. К числу таких методов относятся:

- метод рейтинговых оценок;

- метод категорий предпочтения;

- метод доминирующих характеристик;

- метод оценки затрат.

На сегодняшний день одна из основных задач возврата товаров для интернет-магазинов поиск и выбор провайдеров, работающих в широких географических диапазонах, для транспортировки возвратов по России и зарубежью.

По России возврат товаров компаниями DPD, CДEK, IML и Boxberry осуществляется, в основном, автомобильным транспортом. Тарифы на перевозку воздушным транспортом существенно выше. Курьерские компании для удержания и привлечения новых клиентов сокращают сроки возврата товара, предлагая низкие тарифы на авиаперевозки по некоторым направлениям.

\footnotetext{
1 [Электронный ресурс] URL: https://www.cs-cart.ru/blog/reyting-sluzhb-dostavki-dlya-internet-magazinov/

2 DPD вводит двухчасовой интервал курьерской доставки. [Электронный ресурс] URL: https://oborot.ru/news/dpdvvodit-dvuhchasovoj-interval-kurerskoj-dostavki-i83187.html; Правила по осуществлению доставки. [Электронный реcypc] URL: https://iml.ru/legal/delivery-rules; Курьерская доставка для частных лиц. [Электронный ресурс] URL: https://boxberry.ru/private_customers/kurerskaya-dostavka-dlya-chastnykh-lits/

${ }^{3}$ DPD вводит двухчасовой интервал курьерской доставки. [Электронный ресурс] URL: https://oborot.ru/news/dpdvvodit-dvuhchasovoj-interval-kurerskoj-dostavki-i83187.html
} 
Применяя метод рейтинговых оценок, при выборе компании учитывают сроки доставки при возврате, стоимость, рейтинг компании, сохранность груза, возможности его отслеживания и т. д. При возврате товара метод рейтинговых оценок не полно определяет степень значимости каждого из критериев, т. к. рассматривает компании только с позиции одного какого-либо отдела, например, отдела рекламаций.

При выборе транспортных компаний предлагается воспользоваться расширенным методом методом категорий предпочтения. Будут приняты во внимание оценки ряда структурных подразделений интернет-магазина.

По данным табл. 2 следует вывод, что «тариф на возврат» товара является значимым критерием. Эмпирическим путем была установлена важность применения метода категорий предпочтения при выборе транспортных компаний. Представлена система критериев с оценкой вклада каждого показателя для каждого отдела интернет-магазина. Эту систему можно использовать в методе рейтинговых оценок.

Таблица 2

Выбор курьерской компании для интернет-магазина методом категорий предпочтения

\begin{tabular}{|c|c|c|c|c|c|}
\hline \multirow{2}{*}{$\begin{array}{l}\text { Критерий } \\
\text { выбора }\end{array}$} & \multicolumn{3}{|c|}{$\begin{array}{c}\text { Подразделение компании-владельца } \\
\text { интернет-магазина } \\
\end{array}$} & \multirow{2}{*}{$\begin{array}{c}\text { Вес с } \\
\text { учетом } \\
\text { доли } \\
\text { участия } \\
\end{array}$} & \multirow{2}{*}{ Итоговый вес } \\
\hline & $\begin{array}{l}\text { финансовый } \\
\text { отдел }\end{array}$ & $\begin{array}{c}\text { отдел } \\
\text { продаж }\end{array}$ & $\begin{array}{l}\text { отдел ре- } \\
\text { кламаций }\end{array}$ & & \\
\hline Тариф на возврат & 0,6 & 0,3 & 0,4 & 0,41 & 0,34 \\
\hline Срок возврата & - & 0,3 & 0,6 & 0,39 & 0,32 \\
\hline $\begin{array}{l}\text { Гибкость схемы маршрутиза- } \\
\text { ции перевозок }\end{array}$ & - & 0,2 & 0,4 & 0,26 & 0,22 \\
\hline $\begin{array}{l}\text { Финансовая стабильность } \\
\text { (имидж) }\end{array}$ & 0,5 & - & 0,1 & 0,15 & 0,12 \\
\hline Доля участия подразделения & 0,2 & 0,3 & 0,5 & - & - \\
\hline Итого & - & - & - & 1,21 & 1,00 \\
\hline
\end{tabular}

Применяя метод доминирующих характеристик при возврате товаров, компания сосредотачивается на выборе одного наиболее важного критерия. Можно выбрать один из следующих критериев: тариф на возврат, география доставки и т. п.

Преимуществом метода является его простота, а недостатком - игнорирование остальных критериев, которые могут существенно влиять на оптимизацию возвратной логистики и сокращение издержек. Сопоставление критериев при выборе транспортных компаний для интернетмагазинов представлено в табл. 3.

Таблица 3

Критерии выбора транспортной компании при возвратах товаров в интернет-торговле (по материалам')

\begin{tabular}{|c|c|c|c|c|}
\hline Компания & $\begin{array}{c}\text { Срок возврата, } \\
\text { дни }\end{array}$ & Стоимость возврата, руб. & $\begin{array}{c}\text { География до- } \\
\text { ставки возврата }\end{array}$ & $\begin{array}{c}\text { Страхование гру- } \\
\text { зов, \% от объяв- } \\
\text { ленной стоимости }\end{array}$ \\
\hline DPD & $\begin{array}{c}2-3-\text { Россия } \\
1-6-\text { Европа, } \\
\text { СНГ }\end{array}$ & $\begin{array}{c}305 \text { - по России, } \\
\text { индивидуально - СНГ и Ев- } \\
\text { ропа }\end{array}$ & $\begin{array}{c}\text { Россия, СНГ, Ев- } \\
\text { ропа }\end{array}$ & 0,2 \\
\hline СДЕК & индивидуально & индивидуально & $\begin{array}{c}\text { Россия, СНГ, Гер- } \\
\text { мания, Таиланд }\end{array}$ & 0,75 \\
\hline Boxberry & 10 & $\begin{array}{c}\text { ПВЗ - бесплатно, } \\
\text { курьером - индивидуально }\end{array}$ & Россия & 0,5 \\
\hline IML & 7 & 290 & Россия & индивидуально \\
\hline
\end{tabular}

Проведя сравнительный анализ, следует вывод, что лучшие условия по возврату товаров предлагает компания DPD:

- тариф по России 305 руб.;

- минимальные сроки 2-3 дня;

\footnotetext{
1 Возврат товаров интернет-магазинов. [Электронный ресурc] URL: https://www.dpd.ru/dpd/uslugi-i-tarify/otraslevyeresheniya/vozvrat.do2; Оформление международного возврата в интернет-магазин ASOS. [Электронный ресурс] URL: https://boxberry.ru/international_shipping/vozvrat-tovarov-v-asos/; Обмен и возврат товара. [Электронный ресурс] URL: https://likemyhome.blizko.ru/pages/3846-obmen-i-vozvrat-tovara
} 
- география возврата охватывает Россию, СНГ и Европу.

Стоимость услуг по возврату товара и сроки являются решающими факторами при выборе курьерской компании. Необходимо предлагать также лучшие условия по доставке возвратов: большая территория охвата, низкие тарифы по страхованию грузов. По итогам проведенного анализа такой курьерской компанией является DPD.

Важно учесть, что возвратная логистика связана не только с товарами, не устроившими по каким-либо параметрам покупателя, но и с многооборотной тарой, которая должна возвращаться к грузоотправителю. При рационализации возвратных потоков тары нужно иметь в виду, что при расстояниях свыше 500 км затраты на ее перевозку значительно возрастают, и становится выгоднее производить новую тару, чем применять возвратную [3].

Развитие интернет-торговли в России требует системного подхода к разработке стратегии доставки товаров, формированию тарифов и организации возвратных потоков. При принятии каждого управленческого решения необходимо изучение покупательной способности населения, его пожеланий по уровню обслуживания, стоимости и сроков доставки, мест расположения ПВЗ, наличия конкурентов на рынке интернет-торговли.

\section{Литература}

1. Седых И.А. Рынок интернет-торговли в РФ. https://dcenter.hse.ru/data/2017/03/10/1169536647/202016.pdf.

2. Самусев Н.С. Услуги фулфилмента в логистических цепях поставок товаров для интернет-торговли. Сборник научных трудов «Транспорт и логистика: инновационное развитие в условиях глобализации технологических и экономических связей», Рост. гос. ун-т. путей сообщения. Ростов н/Д, 2018. 489 с. [Электронный ресурс] URL: https://elibrary.ru/item.asp?id=37147848.

3. Павлова Е.И., Мамедова И.А. Возвратные товаропотоки в логистике: причинные связи // Мир транспорта. Том 13. № 5 (60). 2015. С. 124 - 131.

Samusev Nikolai Semenovich, Postgraduate Student, Russian University of Transport (MIIT) (9, Obraztsova St., Moscow, 127994, Russian Federation). E-mail: nssdimon@yandex.ru

Pavlova Elena Ivanovna, PhD in Economics, Professor, Russian University of Transport (MIIT) (9, Obraztsova St., Moscow, 127994, Russian Federation). E-mail: elenaivanovna@bk.ru

\section{ORGANIZATION OF GOODS DELIVERY SUPPLY CHAINS IN ONLINE TRADE CONSIDERING RETURN OF GOODS}

\section{Abstract}

E-trade development in Russia caused the necessity of enhancement of organization of goods delivery. The article discusses current trends in the returns of goods of online trading. The services for the delivery of goods are analyzed using the example of DPD, IML, SEDEC, Boxberry fulfillment operators. The application of the rating method when choosing transport is not fully effective, because it does not take into account the specifics of on-line trade. The use of methods of categories of preferences and rating estimates helps to optimize the return of goods. The main criteria for selecting courier companies while returning goods are proposed.

Keywords: Internet trade, transport companies, method of the dominating characteristics, return of goods, quality of goods, logistic chains, fulfillment-operators, logistics systems, mail and messenger service.

\section{References}

1. Sedyh I.A. Rynok internet-torgovli v RF. https://dcenter.hse.ru/data/2017/03/10/1169536647/202016.pdf.

2. Samusev N.S. Uslugi fulfilmenta $v$ logisticheskih cepyah postavok tovarov dlya internet-torgovli. Sbornik nauchnyh trudov «Transport i logistika: innovacionnoe razvitie v usloviyah globalizacii tekhnologicheskih i ekonomicheskih svyazej», Rost. gos. un-t. putej soobshcheniya. Rostov n/D, 2018. 489 p. - [Elektronnyj resurs] URL: https://elibrary.ru/item.asp?id=37147848.

3. Pavlova E.I., Mamedova I.A. Vozvratnye tovaropotoki v logistike: prichinnye svyazi // Mir trans-porta. Tom 13. № 5 (60). 2015. P. 124 - 131. 